\title{
ACCIONES DE INTERDICCIÓN CONTRA LA PESCA ILEGAL
}

\section{INTERDICTION ACTIONS AGAINST THE ILEGAL FISHING}

\author{
Daniel Da Fieno Jibaja \\ Abogado \\ Empresa Pesquera Exalmar S.A.A. \\ daniel.dafieno@gmail.com \\ Perú, Lima
}

\section{SUMARIO}

- Introducción.

- Antecedentes.

- Decreto Legislativo $N^{\circ} 1393$.

- Conclusiones.

\section{RESUMEN}

El recientemente aprobado Decreto Legislativo que regula las acciones de interdicción en las actividades de pesca ilegal, representa un paso adelante en el fortalecimiento de la lucha contra esta amenaza que vulnera el aprovechamiento sostenible de los recursos hidrobiológicos.

Si bien aún queda mucho trabajo por realizar, constituye un acierto y demuestra un verdadero compromiso e interés por parte del Estado para devolverle a nuestra pesquería el lugar que le corresponde.

Terminar con la informalidad, que afecta a la mayor parte de las actividades productivas de nuestro país, en un sector tan determinante para el desarrollo nacional no es una tarea sencilla; sin embargo, este esfuerzo se suma a las ya desarrolladas labores que, bajo la batuta de la Dirección General de Capitanías y el Ministerio de la Producción, se vienen realizando a lo largo de nuestras 200 millas marinas.

Considero que la idea principal de la inclusión de esta norma en nuestro espectro normativo es más de naturaleza disuasoria que efectiva, toda vez que hasta hace muy poco tiempo, el tema de la lucha contra la informalidad pesquera, no generaba mucho entusiasmo en las autoridades del sector, en la medida que la realidad social vinculada a este tema se constituía como una barrera que muy pocos estaban dispuestos a cruzar.

Hay que hilar muy fino a efectos de no abusar de esta nueva herramienta que, sin duda, generará una serie de retos en su aplicación para las autoridades pero que, de lograrse, contribuirá enormemente para un proceso de formalización que urge.

\section{ABSTRACT}

The recently approved Legislative Decree that regulates interdiction actions in illegal fishing activities represents a step forward in strengthening the fight against this threat that harms the sustainable use of hydrobiological resources.

Although there is still a lot of work to be done, it is a success and demonstrates a real commitment and interest on the part of the State to return our fishery to its rightful place.

End informality, which affects most of the productive activities of our country, in a sector so crucial for national development is not an easy task; However, this effort is added to the already developed tasks that, under the baton of the General Directorate of Captaincies and the Ministry of Production, have been carried out throughout our 200 nautical miles.

I believe that the main idea of the inclusion of this norm in our normative spectrum is more dissuasive than effective, since until very recently, the issue of the fight against fishing informality, did not generate much enthusiasm in the authorities of the sector, to the extent that the social reality linked to this issue was constituted as a barrier that very few were willing to cross. 
It is necessary to spin very thin so as not to abuse this new tool that, without a doubt, will generate a series of challenges in its application for the authorities but that, if achieved, will contribute enormously to a process of formalization that is urgent.

\section{PALABRAS CLAVE}

Ilegal; interdicción; formalización.

\section{KEYWORDS}

Ilegal; interdiction; formalization.

\section{INTRODUCCIÓN}

El presente trabajo tiene por objetivo analizar la entrada en vigencia del Decreto Legislativo $\mathrm{N}^{\circ}$ 1393, que incorpora la figura de la interdicción en las actividades pesqueras ilegales, así como su impacto en un sector que arrastra una fuerte informalidad sobre todo en las pesquerías vinculadas al sector artesanal.

Resulta necesario evaluar si el impacto de esta norma ayudará a mejorar la manera en que se organizan los actores del sector, o si por el contrario solo servirá para profundizar las brechas entre la pesca artesanal y el sector industrial.

Consideramos que el iniciar un debate ya es un avance significativo, debido al silencio que se ha guardado a lo largo de años, sobre una problemática que eldesarrollo macroeconómico del país no ha podido solucionar.

\section{ANTECEDENTES}

Recientemente se incorporó a nuestro espectro normativo un nuevo texto legal. En el marco de las facultades delegadas por el poder legislativo mediante la Ley 30823, se emitió el Decreto Legislativo $\mathrm{N}^{\circ}$ 1393, Decreto Legislativo que regula la interdicción en las actividades ilegales en la pesca.

Según fuentes del Ministerio de la Producción, ente rector de la pesca en el Perú, la informalidad en el sector de pesca artesanal ronda entre el $48 \%$ para el caso de pescadores y $59 \%$ para armadores (Ministerio de la producción, 2018). Al encontrarse al margen de la ley, sus actividades se realizan sin el menor respeto por los criterios de manejo sostenible y protección del medio ambiente. Ello significa un enorme daño a la sostenibilidad de los recursos hidrobiológicos.

En el Perú, la pesca ilegal constituye una grave problemática. Según fuentes de la FAO esta afecta a más de 300000 hombres y mujeres, para quienes la pesca supone su medio de vida fundamental (Organización de las Naciones Unidas para la Alimentación y la Agricultura, 2019).

La falta de orden en las pesquerías de captura no es exclusividad del sector, es una realidad integrada con nuestro día a día y que se sumerge en la cotidianidad de las actividades que realizamos. Para muestra, un botón: las agresiones físicas y verbales a inspectores acreditados por el Ministerio de la Producción y los Gobiernos Regionales son constantes y nos recuerdan a las imágenes cotidianas de transportistas agrediendo a inspectores municipales en plena hora punta. El orden nunca es fácil de asimilar para una sociedad que no acostumbrada a ello, pero es necesario.

La pesca ilegal no es un problema exclusivo del Perú. Según datos de la Organización de las Naciones Unidas para la Alimentación y la Agricultura (FAO), la pesca ilegal, no declarada y no reglamentada (pesca INDNR por sus siglas en inglés) representa hasta 26 millones de toneladas del pescado capturado anualmente, cuyo valor oscila entre los 10,000 y 23,000 millones de dólares americanos. (Organización de las Naciones Unidas para la Alimentación y la Agricultura, 2019)

Estas cifras representan un reto para las autoridades a nivel continental, teniendo en consideración el lugar privilegiado que tiene nuestra región del planeta en cuanto a biodiversidad de especies marinas.

Pero los desafíos y la informalidad no son solo dentro de nuestras fronteras. Cada vez son más frecuentes los operativos en alta mar contra barcos asiáticos que cruzan el globo con el objetivo de pescar dentro de nuestros territorios marítimos.

En marzo del 2016, la armada argentina hundió la embarcación de bandera china YING YUAN 626, la cual fue sorprendida pescando de manera ilegal en una zona económica exclusiva argentina cerca de Puerto Madryn, en la provincia de Chubut, en el sureste de ese país. 
La pesca ilegal existe en todos los tipos y dimensiones de la pesca, muchas veces está asociada al crimen organizado y al narcotráfico, y su impacto a los pescadores formales o de subsistencia es especialmente significativo en países en vías de desarrollo, como el Perú.

La ratificación por parte de nuestro país en el año 2017 del Acuerdo sobre Medidas del Estado Rector del Puerto Destinadas a Prevenir, Desalentar, y Eliminar la Pesca Ilegal, No Declarada y No Reglamentada, adoptado el 22 de noviembre de 2009 en la Conferencia de la Organización de las Naciones Unidas para la Alimentación y la Agricultura, ha significado un hito importante dentro de las acciones que emprenderá nuestro país en la lucha frontal contra la pesca ilegal.

Los países que forman parte del acuerdo deben aplicar una serie de medidas, entre las que destacan las siguientes:

-Los buques pesqueros extranjeros deberán informar con anticipación antes de ingresar al puerto de un país miembro, para lo cual deben identificarse y dar información detallada sobre sus actividades.

-El país que recibe la solicitud puede condicionar su aceptación a una inspección y puede restringir el acceso a sus puertos o servicios a aquellos barcos que tengan indicios de actividades pesqueras ilegales y sancionarlos.

-El país que detecta la pesca ilegal deberá notificar al país que le otorgó bandera y a las organizaciones regionales de ordenamiento pesquero para tomar medidas. (Rumbos de sol y piedra, 2017, párrafos 7,8 y 9).

El plan de acción internacional para prevenir, desalentar y eliminar la pesca ilegal, no declarada y no reglamentada elaborado por la Organización de las Naciones Unidas para la Agricultura y la Alimentación (FAO) establece que cada Estado debería tomar medidas o cooperar para velar que los sujetos nacionales no respalden ni practiquen la pesca ilegal no declarada y no reglamentada, implementando medidas de control.

En los últimos años, en el Perú se ha implementado mecanismos de control que permiten acreditar la correcta trazabilidad de los recursos. Es más, puedo decir, sin temor a equivocarme, que las medidas adoptadas en el control y supervisión de la actividad extractiva son de las más completas, ya que se cuenta con control en todas las etapas del sector desde el monitoreo satelital de las embarcaciones, que permite saber dónde están realizando las calas y advertir cuando las mismas se realizan en zonas prohibidas o suspendidas, hasta la verificación en la zona de ensaque una vez culminada la producción de la harina de pescado, pasando por control en chata, en tolvas, en las pozas y hasta en el transporte del producto hasta su destino final.

La trazabilidad permite saber el origen de los recursos y descartar un origen ilegal, es por ello que países como los Estados Unidos y la Unión Europea han adoptado medidas a fin que a sus mercados únicamente ingresen productos debidamente acreditados por los países de origen; por ejemplo, si alguna empresa peruana desea exportar harina o aceite de pescado a la Unión Europea, deberá contar con un Certificado de Captura debidamente emitido por el Ministerio de la Producción, el cual certifica el origen legal y la trazabilidad del recurso hidrobiológico

Por otro lado, el Gobierno de los Estados Unidos a través de la Agencia Oceánica y Atmosférica (NOAA por sus siglas en inglés) le ha declarado la guerra a la pesca ilegal estableciendo desde hace unos años un programa de trazabilidad a las importaciones de recursos hidrobiológicos que ingresen al mercado norteamericano, con una especial atención para nuestro país cuyas exportaciones de perico constituyen el principal destino de este recurso.

\section{DECRETO LEGISLATIVO $\mathrm{N}^{\circ} 1393$}

Teniendo como contexto, no solo regional sino mundial, la lucha contra la pesca ilegal, no declarada y no reglamentada, el Perú emitió el Decreto Legislativo $\mathrm{N}^{\circ}$ 1393, Decreto que regula la interdicción en las actividades ilegales en pesca.

¿Qué entendemos por acciones de interdicción? Hasta hace unos años se asociaba a este término con los procesos de interdicción contra la minería ilegal en el marco del Decreto Legislativo $\mathrm{N}^{\circ} 1100$, las cuales consisten en acciones conjuntas en las cuales 
participan las fuerzas armadas y policiales, con participación de la Fiscalía, contra aquellos que realizan actividades mineras sin contar con autorización, generando un daño irreparable al ecosistema nacional, principalmente en la región de Madre de Dios.

Las similitudes entre estas dos actividades son diversas: i) ambas actividades constituyen un aprovechamiento irresponsable de recursos naturales; ii) se realizan sin contar con la autorización correspondiente por la autoridad competente; iii) causan un daño irreparable al ecosistema; iv) constituyen una manera de camuflar ingresos económicos por otras actividades ilícitas como el narcotráfico.

Teniendo tantas similitudes, el Estado ha optado por trasladar la experiencia combatiendo la minería ilegal al sector pesquero, sin embargo, si bien cuentan con semejanzas en el plano estructural, cada una de estas actividades tienen particularidades que deben ser bien observadas para augurar un éxito en la implementación de esta norma.

En primer lugar, la norma ha definido lo que se entiende por pesca ilegal (un concepto que no se encontraba regulado por nuestra legislación), el artículo 3 del Decreto Legislativo 1393 lo define como toda actividad que afecta o puede afectar a los recursos hidrobiológicos que se realice con incumplimiento de la normativa de la materia, sea esta administrativa o penal. (Congreso de la República, 2018)

La definición de actividades de pesca ilegal incluye, entre otras, la construcción, instalación o funcionamiento de astilleros sin licencia de funcionamiento, así como la construcción o modificación de embarcaciones y plantas de procesamiento de productos pesqueros sin autorización, y la extracción de recursos hidrobiológicos sin contar con el permiso de pesca correspondiente.

Es importante la inclusión de los astilleros dentro de la definición de los tipos de pesca ilegal, ya que es dentro de estos establecimientos que se inicia la lucha contra esta actividad ilícita, y de aquí provienen las embarcaciones que surcan el océano depredando las riquezas hidrobiológicas del mar de Grau.

Según información de la Dirección General de Capitanías y Guardacostas de la Marina de Guerra del Perú (DICAPI), al año 2017 existen un total de 113 astilleros, varaderos y diques con licencia de operación suspendida, vencida o cancelada; las zonas donde se ha identificado mayor presencia de estas instalaciones son Chimbote, Ilo, Zorritos y Paita. (Ministerio de la Producción, 2018)

Los pescadores ilegales se valen de falsificación de documentos a fin de formalizar sus embarcaciones; mediante procesos de fiscalización posterior, la DICAPI ha identificado que las modalidades más usadas son los certificados de pre matrículas falsas, suplantación de folios y certificados de matrículas falsificados.

El otro punto medular es el caso de las embarcaciones pesqueras. Para entender un poco la importancia del control del esfuerzo pesquero nacional, es importante precisar que, por ejemplo, en el caso de la anchoveta -el recurso más importante con el que contamos en nuestro mar y base de nuestra industria pesquera- se trata de una especie declarada plenamente explotada, es decir solo se permite la actividad extractiva para embarcaciones ya identificadas y registradas por el Ministerio de la Producción.

La industria anchovetera se rige por la denominada Ley de Cuotas regulada por el Decreto Legislativo $\mathrm{N}^{\circ} 1084$ y su reglamento (Presidencia de la República, 2008), en ese sentido, el control se da no solo de las actividades que realizan las embarcaciones pesqueras autorizadas, sino que la cantidad de la biomasa que podrá ser capturada es fijada por el Ministerio de la Producción, previa recomendación del IMARPE.

Otro caso, diametralmente opuesto, es el de la pesca artesanal, sector tradicional de la costa peruana y en la que muchas familias basan su subsistencia. Esta situación es particularmente delicada dado que es el sector más informal en toda la cadena de actividades vinculadas a la pesca.

Tan desordenada es la rama de la pesca artesanal que, a ciencia cierta, no se sabe la cantidad de embarcaciones con la que cuenta la flota nacional. Solo en el norte del país, considerando la industria dedicada a la extracción de pota, se supera largamente el manejo recomendado para un equilibrio que permita una explotación ordenada y sostenible de los recursos hidrobiológicos. 
Hace algunos años se trabajó un proyecto, en el que tuve el honor de participar y es el antecedente inmediato de esta norma. El mismo planteaba que, ante la problemática de la zona de Paita respecto a la flota artesanal dedicada principalmente a la extracción del recurso pota, se abriría una primera etapa de formalización, luego y para aquellos que se resistan a dicho proceso, se aplicaría medidas de interdicción.

En su momento existió una discusión respecto al impacto que podría tener esta norma, sobre todo en el pescador artesanal, aquel que basa su economía en su faena diaria y cuya embarcación constituye su único medio de subsistencia.

Es por ello que considero que la decisión de aplicar las medidas de interdicción debería constituir una última opción, en la medida que estamos hablando del desguace de la embarcación para el caso de los pescadores artesanales y que con ello le quitaríamos su herramienta de trabajo.

El artículo 4 del Decreto Legislativo $N^{\circ} 1393$ nos refiere qué autoridades son las encargadas de llevar a cabo las acciones de interdicción de pesca ilegal. Estas son el Ministerio Público, la Policía Nacional del Perú y la Dirección General de Capitanías y Guardacostas (DICAPI).

Llama poderosamente la atención que no se haya considerado, dentro de las autoridades que tendrán una participación prioritaria en las acciones de interdicción, al ente rector de la pesca en el Perú, el Ministerio de la Producción a través de la Dirección General de Supervisión, Fiscalización y Sanción, siendo esta unidad orgánica la que cuenta con la mayor capacidad operativa de supervisión a lo largo de toda la costa peruana, tanto con personal propio como del Programa de Vigilancia y Control de las Actividades Pesqueras y Acuícolas.

En cuanto a las acciones señaladas en la norma, se hace la precisión respecto a qué tipo de medidas corresponden a cada situación particular, por ejemplo, para el caso de extracción de recursos hidrobiológicos con una embarcación pesquera sin el permiso de pesca correspondiente, procede el desguace de la misma y el decomiso del recurso hidrobiológico que se encuentre en la embarcación.
En lo referente a las medidas frente a actividades de pesca ilegal vinculadas al procesamiento o comercialización de recursos hidrobiológicos, el Decreto Legislativo $\mathrm{N}^{\circ} 1393$ pondera las siguientes acciones en su artículo 6:

Artículo 6.- Acciones de interdicción respecto a las actividades de construcciones de astillero, embarcación pesquera, planta de procesamiento, muelle, desembarcadero pesquero o punto de desembarque, ilegales.

Las acciones de interdicción aplicables respecto a las actividades ilegales señaladas en los incisos 3.1, 3.2, 3.3 y 3.4 del artículo 3 son las siguientes:

6.1 Intervención y descerraje del lugar en el que se advierta la construcción y funcionamiento del astillero o cualquier otra infraestructura que sirva para la construcción de embarcaciones pesqueras; $\mathrm{y}$, decomiso de la maquinaria y equipos que se encuentren en dicho lugar o destrucción de las mismas cuando no resulte viable su decomiso; así como el posterior desguace de la embarcación en el estado en que se encuentre o destrucción de cualquiera de sus partes cuando se verifique la actividad ilegal señalada en el numeral 3.1 del artículo 3.

6.2 Desguace de la embarcación pesquera en el estado en que se encuentre o destrucción de cualquiera de sus partes, cuando se verifique la actividad ilegal señalada en el numeral 3.2 del artículo 3.

6.3 Intervención y descerraje del lugar en el que se advierte la construcción, instalación $u$ operación de la planta de procesamiento pesquero $\mathrm{y}$ posterior decomiso de la maquinaria y equipos que se encuentren en dicho lugar o destrucción de las mismas cuando no resulte viable su decomiso, de verificarse la actividad ilegal señalada en el numeral 3.3 del artículo 3.

6.4 Clausura del muelle, desembarcadero pesquero y punto de desembarque que no cuente con la autorización correspondiente, cuando se verifique la actividad ilegal señalada en el numeral 3.4 del artículo 3. El responsable de la construcción u operación de dichas instalaciones efectúa la remoción inmediata de las mismas, así 
como la restauración de la zona ocupada, asumiendo los costos y riesgos asociados. (Presidencia de la República 2018, Decreto Legislativo $\mathrm{N}^{\circ}$ 1393, Artículo 6).

Estas medidas extremas constituyen una postura que fortalece la legalidad y el principio de autoridad del Estado. Si bien es cierto aplicar estas acciones permitirá, en la medida que se adviertan hechos contrarios a la ley, reducir significativamente las negativas consecuencias de las acciones de pesca ilegal no declarada y no reglamentada, también es cierto que deberán ser aplicadas conforme el procedimiento establecido y evitando cualquier uso arbitrario de las mismas, que constituiría un abuso de autoridad y desluciría la intención de un trabajo serio contra este flagelo.

Otra incorporación que llama la atención es la modificación delCódigo Penal, específicamente el capítulo relacionado a los delitos contra los recursos naturales. La Primera Disposición Complementaria Modificatoria del Código Penal, aprobado por Decreto Legislativo $\mathrm{N}^{\circ}$ 635 el cual establece:

Artículo 308-B.- Extracción y procesamiento ilegal de especies acuáticas.

El que extrae especies de flora o fauna acuática en épocas, cantidades, talla y zonas que son prohibidas o vedadas, o captura especies o las procesa sin contar con el respectivo permiso o licencia o exceda el límite de captura por embarcación, asignado por la autoridad administrativa competente y la ley de la materia, o lo hace excediendo el mismo o utiliza explosivos, o embarcaciones construidas sin autorización o sin licencia, medios químicos $\mathrm{u}$ otros métodos prohibidos o declarados ilícitos, será reprimido con pena privativa de libertad no menor de tres años ni mayor de cinco años. (Presidencia de la República 1991, Decreto Legislativo $\mathrm{N}^{\circ}$ 635, Artículo 308-B).

Este cambio ha originado que nuestra legislación considere delito el hecho de, entre otras cosas, extraer especies de nuestra fauna marina utilizando embarcaciones pesqueras construidas sin autorización o sin la licencia correspondiente.

Actualmente, el Perú forma parte de la Red de Intercambio de Información y Experiencias
Entre Países de América Latina y el Caribe para Prevenir, Desalentar y Eliminar la Pesca INDNR para combatir la pesca ilegal, de la cual hace las veces de Secretario Técnico. Esta red permite a los países compartir información sobre embarcaciones de manera oportuna, con la finalidad de impedir operaciones ilegales de pesca. Además, contribuye al fomento de las acciones de cooperación entre los Estados.

Esta red fue creada en la ciudad de Panamá, los días 4 y 5 de de 2017, en el marco del proyecto Regional FAO TCP/RLA/3604 "Fortalecimiento de las capacidades y las medidas para Prevenir, Desalentar y Eliminar la Pesca Ilegal, No Declarada y No Reglamentada en los países de América Latina". (Organización de las Naciones Unidas para la Alimentación 2017, párrafo 3).

El objetivo principal de la misma es facilitar el intercambio de información y experiencias para la toma de decisiones para prevenir, desalentar y eliminar la Pesca INDNR, a través de la cooperación entre los países participantes.

\section{CONCLUSIONES}

Esta norma es muy ambiciosa sobre lo que busca generar. En primer lugar, otorgar una herramienta de acción a nuestras autoridades a efectos de combatir frontalmente las acciones de pesca ilegal, no declarada y no reglamentada en mar peruano, métodos que antes de la vigencia de esta norma podrían considerarse como abusivos o confiscatorios ahora constituyen una correcta metodología de trabajo dentro del marco legal otorgado.

Por otro lado, es importante reconocer los esfuerzos que han hecho las autoridades peruanas a efectos de regularizar la situación de la pesca en el país, principalmente de la pesca artesanal, ya que se ha creado programas de formalización como el Sistema de Formalización Pesquera Artesanal (SIFORPA) y la Ley que crea el Seguro Obligatorio Del Pescador Artesanal (SOPA) que constituyen mecanismos importantes para un adecuado control y crecimiento de la pesca artesanal.

Considero que esta norma tiene un fin más disuasivo que práctico y lo que buscará es generar una herramienta que el Estado podrá tener al alcance para utilizar, a la par de un nuevo plan de formalización, a efectos de 
disminuir la presencia de embarcaciones sin permiso de pesca, cuyo impacto en nuestro ecosistema es nefasto.

El Perú ha asumido una posición de liderazgo en este tema, y no podía ser de otra manera. La riqueza única del mar de Grau amerita tomar todas las previsiones que correspondan a efectos de resguardar su integridad y su variedad hidrobiológica. El mar peruano es probablemente el más rico del mundo y es tarea de todos el protegerlo.

\section{FUENTES DE INFORMACIÓN}

\section{Fuentes electrónicas}

Ministerio de la Producción (2018). Exposición de Motivos del Decreto Legislativo $\mathrm{N}^{\circ}$ 1393. Recuperado de http://spij.minjus.gob. pe/Graficos/Peru/2018/Setiembre/06/EXPDL-1393.pdf

Organización de las Naciones Unidas para la Alimentación y la Agricultura (2019). Perú contará con Plan de Acción frente a la pesca ilegal. Recuperada del sitio de internet: http:// www.fao.org/peru/noticias/detail-events/ $\mathrm{es} / \mathrm{c} / 1181840 /$

Organización de las Naciones Unidas para la Alimentación y la Agricultura (2017). Funcionarios del Ministerio de Acuacultura y Pesca se capacitan para el desarrollo sostenible de la actividad pesquera en Ecuador. Recupero del sitio de internet: http://www.fao.org/ ecuador/noticias/detail-events/ru/c/903608/

Rumbos de Sol y Piedra (2017). Perú firmará tratado internacional contra la pesca ilegal. Recuperado del sitio en internet: https://www. rumbosdelperu.com/ambiente/10-05-2017/ peru-firmara-tratado-internacional-contra-lapesca-ilegal/.

\section{Fuentes legales}

Congreso de la República (2018). Ley $\mathrm{N}^{\circ}$ 30823. Ley que delega en el poder ejecutivo la facultad de legislar en materia de gestión económica y competitividad, de integridad y lucha contra la corrupción, de prevención y protección de personas en situación de violencia y vulnerabilidad y de modernización de la gestión del Estado. En Diario oficial El Peruano, Lima, Perú.

Presidencia de la República (1991). Decreto Legislativo $\mathrm{N}^{\circ}$ 635. Código Penal. En Diario oficial El Peruano, Lima Perú.

Presidencia de la República (2008). Decreto Legislativo $\mathrm{N}^{\circ}$ 1084. Ley sobre límites máximas de captura por embarcación. En Diario oficial El Peruano, Lima, Perú.

Presidencia de la República (2012). Decreto Legislativo $\mathrm{N}^{\circ}$ 1100. Decreto Legislativo que regula la interdicción de la minería ilegal en toda la república y establece medidas complementarias. En Diario oficial El Peruano, Lima, Perú.

Presidencia de la República (2018). Decreto Legislativo $\mathrm{N}^{\circ}$ 1393. Decreto Legislativo que regula la interdicción en las actividades ilegales en pesca. En Diario oficial El Peruano, Lima, Perú. 